\title{
INFLUENCE OF BACKGROUND SHADE AND RESIN CEMENT ON COLOR CHANGE OF RESIN MATRIX CERAMICS
}

\author{
Burcu Batak', Caner Öztürk² \\ 'Department of Prosthodontics, Faculty of Dentistry, Ankara University, Ankara, Turkey \\ 2Department of Prosthodontics, Faculty of Dentistry, Hatay Mustafa Kemal University, Hatay, Turkey
}

\begin{abstract}
INTRODUCTION: Color stability of dental restorations is a major factor in achieving successful aesthetic outcomes. ОвJеCтIVEs: The aim of the study was to evaluate the effect of resin cement and different composite resin background shades on the change of color of resin matrix ceramics (RMCs).

MATERIAL AND METhods: Three different RMCs were used in this study, including Vita Enamic (EN), GC Cerasmart (CS), and Lava Ultimate (LU). Ten specimens of each RMC with a dimension of $12 \times 14 \times 1 \mathrm{~mm}$ were prepared from CAD-CAM blocks, and 3 specimens from each RMC with a dimension of $12 \times 14 \times 4$ mm were prepared as control group. Color measurements were performed on 3 different shaded (A1, A2, and A3) composite resin backgrounds. To evaluate the effect of resin cement, color differences between RMC specimens with and without resin cement were calculated. Data were analyzed by using two-way ANOVA and one-way ANOVA tests, with $\alpha=0.05$.

RESULTS: In the groups with A2 and A3 shaded composite resin backgrounds, the highest color change values were observed in the EN group $(p<0.05)$. For all RMC materials, the highest color change values were observed in the specimens with A1 background $(p<0.05)$. The lowest color change after cementation was observed in the CS group $(p<0.05)$.

Conclusions: Composite resin background shades significantly affected the color of RMC materials. Color changes after cementation were above clinically acceptable level in all groups of specimens.
\end{abstract}

KEY WORDS: CAD-CAM, colorimetry, dental prosthesis, resin cements.

J Stoma 2021; 74, 3: 160-165

DOI: https://doi.org/10.5114/jos.2021.108956

\section{INTRODUCTION}

Demands for esthetic restorations are gradually increasing [1]. Although, several computer-aided design and computer-aided manufacturing (CAD-CAM) systems combining esthetics and strength to handle different clinical situations are currently on the market, it is still a great challenge for clinicians to produce naturallooking restorations $[1,2]$. Moreover, optical properties of a restoration similar to natural teeth are crucial for long-term success as well as mechanical properties [3]. Glass-ceramics are considered to be ideal restorative materials, with their advantages including enamel-like optical features, wear resistance, biocompatibility, and esthetics $[4,5]$. However, some glass-ceramics are prone to fracture and can cause wear of antagonist dentition $[6,7]$. CAD-CAM resin matrix ceramics (RMCs), developed as an alternative to CAD-CAM glass-ceramic re-

\section{JOURNAL OF} STOMATOLOGY CZASOPISMO STOMATOLOGICZNE

AdDRESS FOR CORRESPONDENCE: Dr. Caner Öztürk, Department of Prosthodontics, Faculty of Dentistry, Hatay Mustafa Kemal University, Tayfur Sökmen Kampüsü Alahan-Antakya, Hatay, 31060, Turkey, phone: +905057589834, e-mail: dtcanerozturk@gmail.com

ReCEIVED: 02.04.2021 • ACCEPTED: 30.05.2021 • PUBLISHED: 30.08.2021 
storative materials, integrate the characteristics of polymers and ceramics [8]. RMCs have the advantages of elasticity modulus close to dentin, easier milling, and wear resistance $[9,10]$. Additionally, these materials can be repaired intra-orally [8], and cause minimal abrasion of antagonist teeth [11]. RMCs have mechanical properties between ceramics and composite resin, and have higher strength than ceramics under compressive loading [12-14].

\section{OBJECTIVES}

The final optical characteristic of a restoration depends on several factors, such as chemical composition [15], translucency [16], thickness, layering of the ceramic system used [17], and optical behavior of the luting agent [18]. Additionally, Raptis et al. [19] reported that the underlying structure primarily influences final appearance of ceramic restorations. Previously published studies have investigated the effect of resin cement as well as substrate color on optical properties of glassceramic restorations [17, 18, 20-24]. However, the influence of composite resin background shades and resin cement on the optical properties of RMC materials remains unclear. Therefore, the aim of the study was to evaluate the effect of dual-cure self-adhesive resin cement and composite resin background shades on the change of color of RMCs. The first null hypothesis of the study was that composite resin background shades would have no effect on the color change of RMCs, and the second null hypothesis of the study was that resin cement would have no effect on the color change of RMCs.

\section{MATERIAL AND METHODS}

Three different commercially available RMCs were used in this study, including Vita Enamic (EN; Vita
Zahnfabrik, Bad Säckingen, Germany), GC Cerasmart (CS; GC Corp., Tokyo, Japan), and Lava Ultimate (LU; 3M ESPE, St. Paul, Minnesota, USA) (Table 1). Ten specimens of each RMC with a dimension of $12 \times 14 \times 1 \mathrm{~mm}$ were prepared from CAD-CAM blocks using a precision cutting machine (Micracut 201; Metkon Instruments Inc., Bursa, Turkey). The sample size of the groups was determined according to a study conducted by Sonza et al. [25]. In addition, 3 specimens from each RMC with a dimension of $12 \times 14 \times 4 \mathrm{~mm}$ were prepared as a control group, and $L^{*}, a^{*}$, and $b^{*}$ values of the control groups were measured with a spectrophotometer (VITA Easyshade ${ }^{\circledR}$ Advance 4.0; VITA Zahnfabrik H. Rauter GmbH \& Co.KG., Bad Säckingen, Germany) under a standardized condition (D65 illumination and neutral grey background, $L^{*}=71.6$, $a^{*}=0.04$, and $\left.b^{\star}=0.05\right)\left(E N: L^{*}=76.47, a^{*}=-1.20\right.$, and $\mathrm{b}^{\star}=17.37$; LU: $\mathrm{L}^{\star}=79.2, \mathrm{a}^{\star}=-1.7$, and $\mathrm{b}^{\star}=18.17$; CS: $L^{\star}=73.43, a^{\star}=-0.7$, and $\left.b^{\star}=13.13\right)$. Outer surfaces of the specimens were polished according to manufacturers' instructions (Vita Enamic, Vita Enamic Polishing Set, Vita Zahnfabrik, Bad Säckingen, Germany; GC Cerasmart, Dia Polisher, GC Dental Products Europe, Leuven, Belgium; Lava Ultimate Sof-Lex, 3M ESPE, St. Paul, Minnesota, USA), and no treatment was applied to inner surfaces of the specimens. Final dimensions of the specimens were determined with a digital caliper (Digital Micrometer IP65, Mitutoyo Europe GmbH, Neuss, Germany).

Thirty-three composite resin (Clearfil Majesty Esthetic; Kuraray Noritake Dental Inc., Okayama, Japan) specimens with different shades (A2:31, A1:1, and A3:1) were served as backgrounds for color measurements. Specimens with a dimension of $12 \times 14 \times 3 \mathrm{~mm}$ were prepared using a standardized Teflon mold and light-polymerized for 40 seconds on each side according to manufacturer's recommendations using a LED

TABLE 1. Overview of the materials used in the study

\begin{tabular}{|c|c|c|c|c|c|}
\hline Material & Type & Composition & Manufacturer & Shade & LOT \\
\hline $\begin{array}{l}\text { Vita Enamic } \\
\text { (EN group) }\end{array}$ & $\begin{array}{l}\text { Polymer-infiltrated hybrid } \\
\text { ceramic (glass ceramic in a resin } \\
\text { interpenetrating matrix) }\end{array}$ & $\begin{array}{l}86 \text { wt } \% \text { feldspathic ceramic enriched with } \\
\mathrm{Al}_{2} \mathrm{O}_{3}, 14 \mathrm{wt} \% \text { polymer (UDMA, TEGDMA) }\end{array}$ & $\begin{array}{l}\text { Vita Zahnfabrik, } \\
\text { Bad Säckingen, } \\
\text { Germany }\end{array}$ & 2M2-HT EM-14 & 78540 \\
\hline $\begin{array}{l}\text { CeraSmart }{ }^{\mathrm{TM}} 270 \\
\text { (CS group) }\end{array}$ & Force absorbing hybrid ceramic & $\begin{array}{l}\text { Bis-MEPP, nano-particle-filled resin (UDMA, } \\
\text { DMA), } 71 \text { wt\% silica and barium glass filler }\end{array}$ & $\begin{array}{l}\text { GC Corp., Tokyo, } \\
\text { Japan }\end{array}$ & A2 HT 14 & 1906056 \\
\hline $\begin{array}{l}\text { Lava Ultimate } \\
\text { (LU group) }\end{array}$ & Resin nano-ceramic & $\begin{array}{l}80 \text { wt } \% \text { nano-ceramic, } 20 \text { wt } \% \text { resin } \\
\text { (Bis-GMA, UDMA, Bis-EMA, TEGDMA) }\end{array}$ & $\begin{array}{l}\text { 3M ESPE, St. Paul, } \\
\text { MN, USA }\end{array}$ & A2 HT 14 & N554516 \\
\hline $\begin{array}{l}\text { Clearfil Majesty }^{\mathrm{TM}} \\
\text { Esthetic }\end{array}$ & Composite resin & $\begin{array}{l}\text { Transparent organic fillers, radiopaque } \\
\text { micro-fillers, and high refractive index } \\
\text { matrix (filler contents: } 78 \text { wt } \% \text { and } 66 \% \text { vol) }\end{array}$ & $\begin{array}{l}\text { Kuraray Noritake } \\
\text { Dental Inc., } \\
\text { Okayama, Japan }\end{array}$ & $\begin{array}{l}\text { A1 } \\
\text { A2 } \\
\text { A3 }\end{array}$ & $\begin{array}{l}\text { 6E0076 } \\
440171 \\
7 E 0144\end{array}$ \\
\hline G-CEM LinkAce ${ }^{T M}$ & $\begin{array}{l}\text { Dual-cure self-adhesive resin } \\
\text { cement }\end{array}$ & $\begin{array}{l}\text { HEMA-free, fluoro-alumino-silicate glass } \\
(60-70 \%) \text {, urethane dimethacrylate } \\
\text { (12-17\%), dimethacrylate (12-17\%), silicon } \\
\text { dioxide (3-8\%), initiator, inhibitor, pigment }\end{array}$ & $\begin{array}{l}\text { GC Corp., Tokyo, } \\
\text { Japan }\end{array}$ & $\mathrm{A} 2$ & 1808031 \\
\hline
\end{tabular}


polymerization unit (Radii; SDI Limited, Victoria, Australia). A holding tip was used to standardize the distance between LED polymerization unit and specimens. Then, bonding surfaces of the specimens were polished with wet 800-grit silicon carbide papers (Buehler; Lake Bluff, IL, USA) and ultrasonically cleaned for $10 \mathrm{~min}$. Final thicknesses of the specimens were determined with a digital caliper. The specimens were stored in distilled water for 24 hours at $37^{\circ} \mathrm{C}$. To evaluate the effect of a background shade, the RMC specimens were placed on differently shaded backgrounds (A1:1, A2:1, and A3:1), and color measurements were performed. Optical continuity between the specimens and backgrounds were achieved by using one thin drop glycerin solution, and color measurements were done using a spectrophotometer under a standardized condition, as previously stated. Three measurements were performed from each specimen, and the spectrophotometer was calibrated after every measurement according to manufacturer's instructions. Color differences between the specimens with different backgrounds, and control group for each RMC were calculated with CIEDE2000 (2: $1: 1)$ formula [26] as stated below:

$\begin{aligned} & \text { CIEDE } \\ & 2000\end{aligned}=\sqrt{\left(\frac{\Delta \mathrm{L}^{\prime}}{\mathrm{k}_{\mathrm{L}} \mathrm{S}_{\mathrm{L}}}\right)^{2}+\left(\frac{\Delta \mathrm{C}^{\prime}}{\mathrm{k}_{\mathrm{C}} \mathrm{S}_{\mathrm{C}}}\right)^{2}+\left(\frac{\Delta \mathrm{H}^{\prime}}{\mathrm{k}_{\mathrm{H}} \mathrm{S}_{\mathrm{H}}}\right)^{2}+R_{T}\left(\frac{\Delta \mathrm{C}^{\prime}}{\mathrm{k}_{\mathrm{C}} \mathrm{S}_{\mathrm{C}}}\right)+\left(\frac{\Delta \mathrm{H}^{\prime}}{\mathrm{k}_{\mathrm{H}} \mathrm{S}_{\mathrm{H}}}\right)}$

To evaluate the effect of resin cement, the RMC specimens were placed on an A2 shaded backgrounds $(n=30)$, and color measurements were performed before cementation without drop of glycerin solution. Then, the specimens were cemented using an A2 shaded resin cement (G-CEM LinkAce ${ }^{\mathrm{rm}}$; GC Corp., Tokyo, Japan) according to manufacturer's instructions. A Teflon mold was used to create a standardized $0.1 \mathrm{~mm}$ cement thickness. After cementation, the specimens were stored in distilled water for 24 hours at $37^{\circ} \mathrm{C}$, and then, color measurements were performed. Color differences between the cemented and non-cemented specimens were calculated using CIEDE2000 $(2: 1: 1)$ formula. Color difference values were compared only with the $50: 50 \%$ acceptability thresholds (AT) for CIEDE2000 $(2: 1: 1)$ as 1.78 units [26].

\section{STATISTICAL ANALYSIS}

Statistical software (SPSS 19; SPSS, IBM, Chicago, USA) was used to analyze the data. Normality of the data was assessed using Shapiro-Wilk test, while Levene's test was used to evaluate homogeneity. The effect of the background on RMCs color change was evaluated with two-way ANOVA test and post-hoc Tukey's test with Bonferroni corrections. The effect of cement on color change of the RMCs was evaluated using one-way ANOVA and post-hoc Tukey's comparison test. Significance level was set as 0.05 .

\section{RESULTS}

According to the statistical analysis conducted, material and background factors had significant effects on the color change values, and the interaction between material and background factors was also found to be significant $(p<0.05)$. The mean $( \pm$ SD) color change values of the groups are shown in Table 2. In most of the groups with different shaded composite resin backgrounds, the highest color change values were observed in the EN group (Table 2). For the LU and EN groups, the highest color change was observed in the specimens with A1 background, and no significant difference was found between the specimens with A2 and A3 backgrounds $(p>0.05)$ (Table 2). For the CS group, the lowest color change values were observed in the specimens with A3 background, while the highest color change occurred in the specimens with A1 background $(p<0.05)$ (Table 2). Only color change values for the CS and LU groups specimens with A3 background were clinically acceptable (Figure 1).

The color changes after cementation were above clinically acceptable level for all the groups (Figure 1). Statistically significant differences were observed among color change values of the groups after the cementation $(p<0.05)$. The lowest color change after cementation was observed in the CS group $(p<0.05)$, while no significant difference was determined between the LU and EN groups $(p>0.05)$ (Table 2$)$.

\section{DISCUSSION}

In the present study, different composite resin background shades and resin cement significantly affected color change of the RMCs. Therefore, the first null hypothesis of the study that composite resin background shades would have no effect on the color change of RMCs, and the second null hypothesis of the study that

TABLE 2. Comparison of mean ( \pm SD) color change values for the study groups

\begin{tabular}{|c|c|c|c|}
\hline & \multicolumn{3}{|c|}{ Background } \\
\hline EN & $2.92( \pm 0.12)^{A B, a}$ & $2.70( \pm 0.16)^{A, b}$ & $2.52( \pm 0.06)^{A, b}$ \\
\hline CS & $2.99( \pm 0.23)^{\mathrm{A}, \mathrm{a}}$ & $2.18( \pm 0.28)^{\mathrm{B}, \mathrm{b}}$ & $1.43( \pm 0.22)^{B, c}$ \\
\hline LU & $2.55( \pm 0.31)^{\mathrm{B}, \mathrm{a}}$ & $1.83( \pm 0.25)^{c, b}$ & $1.75( \pm 0.29)^{\mathrm{B}, \mathrm{b}}$ \\
\hline \multicolumn{4}{|c|}{ Cemented } \\
\hline EN & & $2.69( \pm 0.03)^{A}$ & \\
\hline CS & & $1.98( \pm 0.35)^{\mathrm{B}}$ & \\
\hline LU & & $2.89( \pm 0.30)^{A}$ & \\
\hline
\end{tabular}

Values are presented in mean $\pm S D$

EN - Vita Enamic, CS - Cerasmart 270, LU - Lava Ultimate.

${ }^{*}$ Different superscript uppercase letters in columns and lower case in rows indicate statistical significance $(p<0.05)$. 


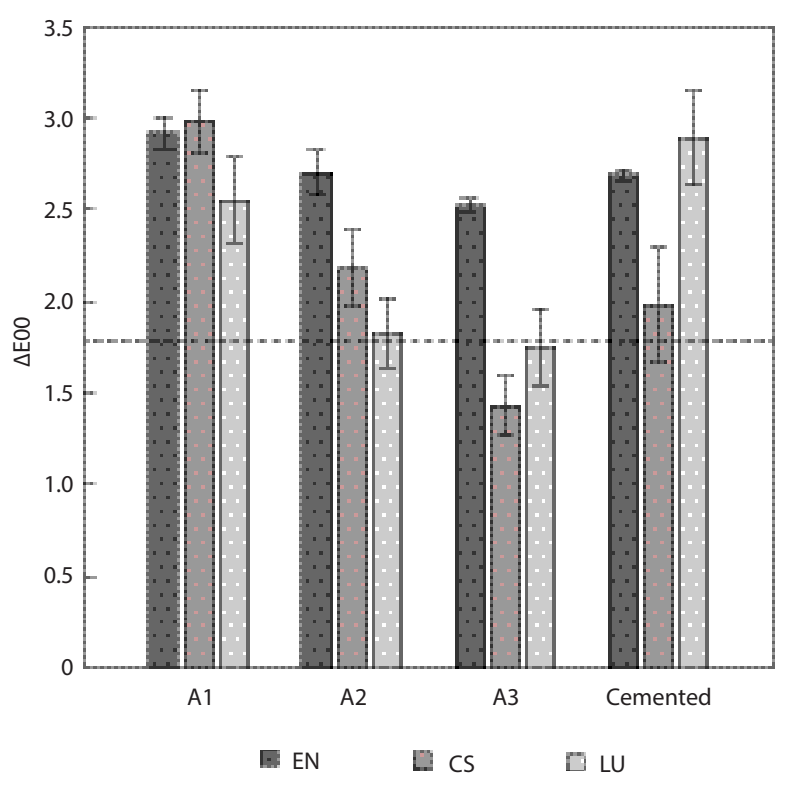

FIGURE 1. Mean color change ( $\triangle \mathrm{E} 00)$ values with $95 \%$ confidence intervals for the groups and acceptability thresholds (AT:1.78) for CIEDE2000 (2:1:1) formula

resin cement would have no effect on the color change of RMCs, were both rejected.

Different color difference formulas have been used in dental research $[15,27,28]$, and in a recent study by Paravina et al. [28], CIEDE2000 color difference formula has been recommended. Additionally, a variety of thresholds have been reported in previous studies to evaluate color change values for restorative materials $[26,28,29]$. In the present study, color change values were calculated with CIEDE2000 $(2: 1: 1)$ formula, as recommended in a study by Perez et al. [26].

Previous studies have demonstrated that the final color of restorations was primarily influenced by the thickness of restorative materials $[1,18,20,23,24]$. Although, the thickness of ceramic restorations should be at least $2 \mathrm{~mm}$ to avoid being affected by underlying structure [21], most minimally invasive restorations, e.g., laminate veneers, are less than $2 \mathrm{~mm}$ thick. Azer et al. [22] examined differently shaded (transparent and opaque) ceramic laminate veneer specimens of $0.5 \mathrm{~mm}$ in thickness, and $\mathrm{A} 3$ and $\mathrm{C} 4$ shaded composite resin backgrounds. In agreement with the present study results, the authors concluded that the examined shade of ceramic laminate veneer was significantly affected when the color of supporting background was changed [22]. Çömlekoğlu et al. [24] evaluated multilayered glass-ceramic specimens with 2 thicknesses $(0.55$ and $0.8 \mathrm{~mm}$ ) using A1 and A3.5 shaded resin backgrounds, two resin cement colors (dark and light), and one resin cement control group (translucent). The authors indicated critical thickness of $0.80 \mathrm{~mm}$ for ceramic veneers to mask background color [24]. In the present study, in order to evaluate the color change affected by the underlying structure, the thickness of the RMC specimens was determined as $1 \mathrm{~mm}$, according to previous studies [10, 24, 30-32].

The optical properties of dental materials may be influenced by composition and microstructure [13]. In the present study, the color change values depended on the color difference between each of the backgrounds and their control group with a 4-mm thickness. Color measurements of the control specimens showed that the investigated RMC materials had different $L^{*}, a^{*}$, and $\mathrm{b}^{*}$ color coordinates, despite being designated to A2 HT color. The lowest color changes were observed in the GC specimens with A3 background, while the highest color changes were noted in all RMC specimens with A1 background. The results of the present study can be interpreted in consideration of the optical properties of RMC materials tested and the differences in brightness of the background shades, which are deemed the most noticeable esthetic errors [33]. The color change values for the CS and LU specimens with A3 backgrounds only were clinically acceptable. Achieving clinically acceptable values with A3 background rather than $\mathrm{A} 2$ background could be related to a lower brightness of A3 shaded background and microstructure of the composite resin background that contained organic filler with high transparency and refractive index matrix. Additionally, the spectrophotometer used in this study that measured spectral reflectance of the color of specimens [34] could be more susceptible to measure the color of backgrounds with higher brightness. Furthermore, Lee et al. [35] reported that color coordinates of similar shaded restorative materials differ by brands and types. Thus, in agreement with Lee et al. [35], the disparity of similar shades of different brands of restorative materials can also attribute to the differences within the investigated groups of specimens. Similar to the present study, Önöral et al. [36] examined optical properties of RMC materials. But contrary to the results of the present research, the authors reported lowest color change values for EN, which was considered related to translucency of the examined RMC blocks. However, this study differs from the present one regarding translucency characteristics of tested RMC blocks and methodology applied [36]. Opposite to the results of the present study, Chaiyabutr et al. [23] concluded that changing substrate color from lighter to darker, results in an increase of color change values. It should be noted that the study by Chaiyabutr et al. [23] also differed from the present study regarding study design and materials tested.

Several investigations preferred resin cements approximately $0.1 \mathrm{~mm}$ in thickness for evaluating stress distribution in veneer restorations [37] and optical properties of resin luting cement [38, 39]. According to previous research [37-39], the thickness of the cement was determined as $0.1 \mathrm{~mm}$ in the present study. In an agreement with previous studies $[38,39]$, the results of the present research revealed that $0.1 \mathrm{~mm}$ thick 
cement layer significantly affected the change of color $(p<0.05)$. Color change values after the cementation were above clinically acceptable levels in all the investigated groups. The lowest color change after the cementation was observed in the CS group. This result could be explained by differences in translucency and color parameters of the materials and cement used in the present study. However, previous studies $[40,41]$ reported closer translucency parameter values for high translucency (HT) RMC materials of $1 \mathrm{~mm}$ in thickness. Therefore, the lowest color change in the CS group may be related to the shade matching and similar color parameters of the CS specimens as well as the cement used, which were all produced by the same manufacturer.

The esthetic appearance can be affected by a chemical composition and color of resin cement. One of the limitations of the present study was that only 1 type (dualcure) and 1 shade (A2) cement were used to evaluate the color changes after the cementation. Moreover, the lack of simulated oral environment for in vitro studies was another limitation for the present study. Therefore, the effect of cement shade and polymerization type on the color changes for RMC materials should be validated by further research using different cement shade variations and polymerization techniques.

\section{CONCLUSIONS}

Within the limitations of this in vitro study, changing the background color from a lighter (A1) to darker (A3) resulted in a decreased color change values for the tested resin matrix ceramic materials. The color changes after the cementation were above clinically acceptable level in all the investigated groups of specimens, while the GC group demonstrated the lowest color change.

\section{CONFLICT OF INTEREST}

The authors declare no potential conflicts of interest with respect to the research, authorship, and/or publication of this article.

\section{References}

1. Son HJ, Kim WC, Jun SH, Kim YS, Ju SW, Ahn JS. Influence of dentin porcelain thickness on layered all-ceramic restoration color. J Dent 2010; 38 Suppl 2: e71-e77.

2. Conrad HJ, Seong WJ, Pesun IJ. Current ceramic materials and systems with clinical recommendations: a systematic review. J Prosthet Dent 2007; 98: 389-404.

3. Blatz MB. Long-term clinical success of all-ceramic posterior restorations. Quintessence Int 2002; 33: 415-426.

4. Duarte S, Sartori N, Phark JH. Ceramic-reinforced polymers: CAD/CAM hybrid restorative materials. Curr Oral Health Rep 2016; 3: 198-202.

5. Vichi A, Louca C, Corciolani G, Ferrari M. Color related to ceramic and zirconia restorations: a review. Dent Mater 2011; 27: 97-108.
6. Kurtulmus-Yilmaz S, Cengiz E, Ongun S, Karakaya I. The effect of surface treatments on the mechanical and optical behaviors of CAD/CAM restorative materials. J Prosthodont 2019; 28: e496-503.

7. Yoshihara K, Nagaoka N, Maruo Y, et al. Sandblasting may damage the surface of composite CAD-CAM blocks. Dent Mater 2017; 33: e124-135.

8. Gracis S, Thompson V, Ferencz J, Silva N, Bonfante E. A new classification system for all-ceramic and ceramic-like restorative materials. Int J Prosthodont 2016; 28: 227-235.

9. Stawarczyk B, Liebermann A, Eichberger M, Güth JF. Evaluation of mechanical and optical behavior of current esthetic dental restorative CAD/CAM composites. J Mech Behav Biomed Mater 2015; 55: 1-11.

10. Ioannidis A, Mühlemann S, Özcan M, Hüsler J, Hämmerle CHF, Benic GI. Ultra-thin occlusal veneers bonded to enamel and made of ceramic or hybrid materials exhibit load-bearing capacities not different from conventional restorations. J Mech Behav Biomed Mater 2019; 90: 433-440.

11. Kunzelmann KH, Jelen B, Mehl A, Hickel R. Wear evaluation of MZ100 compared to ceramic CAD/CAM materials. Int J Comput Dent 2001; 4: 171-184.

12. Della Bona A, Corazza PH, Zhang Y. Characterization of a polymer-infiltrated ceramic-network material. Dent Mater 2014; 30: 564-569.

13. Johnson AC, Versluis A, Tantbirojn D, Ahuja S. Fracture strenght of CAD/CAM composite and composite-ceramic occlusal veneers. J Prosthodont Res 2014; 58: 107-114.

14. Dirxen C, Blunck U, Preissner S. Clinical performance of a new biomimetic double network material. Open Dent J 2013; 7 : 118-122.

15. Della Bona A, Pecho OE, Ghinea R, Cardona JC, Pérez MM. Colour parameters and shade correspondence of CAD/CAM ceramic systems. J Dent 2015; 43: 726-734.

16. Della Bona A, Nogueira AD, Pecho OE. Optical properties of CAD-CAM ceramic systems. J Dent 2014; 42: 1202-1209.

17. Basegio MM, Pecho OE, Ghinea R, Perez MM, Della Bona A. Masking ability of indirect restorative systems on tooth-colored resin substrates. Dent Mater 2019; 35: e122-e130.

18. Kürklü D, Azer SS, Yilmaz B, Johnston WM. Porcelain thickness and cement shade effects on the colour and translucency of porcelain veneering materials. J Dent 2013; 41: 1043-1050.

19. Raptis NV, Michalakis KX, Hirayama H. Optical behavior of current ceramic systems. Int J Periodontics Restorative Dent 2006; 26: 31-41.

20. Pires LA, Novais PM, Araújo VD, Pegoraro LF. Effects of the type and thickness of ceramic, substrate, and cement on the optical color of a lithium disilicate ceramic. J Prosthet Dent 2017; 117: 144-149.

21. Vichi A, Ferrari M, Davidson CL. Influence of ceramic and cement thickness on the masking of various types of opaque posts. J Prosthet Dent 2000; 83: 412-417.

22. Azer SS, Rosenstiel SF, Seghi RR, Johnston WM. Effect of substrate shades on the color of ceramic laminate veneers. J Prosthet Dent 2011; 106: 179-183.

23. Chaiyabutr Y, Kois JC, Lebeau D, Nunokawa G. Effect of abutment tooth color, cement color, and ceramic thickness on the resulting optical color of a CAD/CAM glass-ceramic lithium disilicatereinforced crown. J Prosthet Dent 2011; 105: 83-90.

24. Çömlekoğlu ME, Paken G, Tan F, et al. Evaluation of different thickness, die color, and resin cement shade for veneers of multilayered CAD/CAM blocks. J Prosthodont 2016; 25: 563-569.

25. Sonza QN, Della Bona A, Pecho OE, Borba M. Effect of substrate and cement on the final color of zirconia-based all-ceramic crowns. J Esthet Restor Dent 2021; 33: 891-898.

26. Del Mar Perez M, Ghinea R, Herrera LJ, et al. Dental ceramics: a CIEDE2000 acceptability thresholds for lightness, chroma and hue differences. J Dent 2011; 39: e37-e44.

27. Johnston WM. Color measurement in dentistry. J Dent 2009; 37 Suppl 1: e2-e6. 
28. Paravina RD, Pérez MM, Ghinea R. Acceptability and perceptibility thresholds in dentistry: a comprehensive review of clinical and research applications. J Esthet Restor Dent 2019; 31: 103-112.

29. Paravina RD, Ghinea R, Herrera LJ, et al. Color difference thresholds in dentistry. J Esthet Restor Dent 2015; 27 Suppl 1: S1-9.

30. Xing W, Jiang T, Ma X, et al. Evaluation of the esthetic effect of resin cements and try-in pastes on ceromer veneers. J Dent 2010; 38 Suppl 2: e87-e94.

31. Maeder M, Pasic P, Ender A, Özcan M, Benic GI, Ioannidis A. Load-bearing capacities of ultra-thin occlusal veneers bonded to dentin. J Mech Behav Biomed Mater 2019; 95: 165-171.

32. Ruggiero MM, Soares Gomes R, Pedroso Bergamo ET, Freitas MIM, Bonfante EA, Del Bel Cury AA. Resin-matrix ceramics for occlusal veneers: effect of thickness on reliability and stress distribution. Dent Mater 2021; 37: e131-e139.

33. Niu E, Agustin M, Douglas RD. Color match of machinable lithium disilicate ceramics: effects of foundation restoration. J Prosthet Dent 2013; 110: 501-509.

34. ISO Standard TR 28642/2011. Dentistry-Guidance on colour measurement. Available at: https://www.iso.org/standard/44846. html.

35. Lee YK, Yu B, Lee SH, Cho MS, Lee CY, Lim HN. Shade compatibility of esthetic restorative materials - a review. Dent Mater 2010; 26: 1119-1126.

36. Önöral Ö, Günal-Abduljalil B, Ongun S. Effect of color of the cement and the composite resin foundation on the resultant color of resin-matrix ceramics. J Prosthet Dent 2021; 125: 351.e1-351.e7.

37. Magne P, Versluis A, Douglas WH. Effect of luting composite shrinkage and thermal loads on the stress distribution in porcelain laminate veneers. J Prosthet Dent 1999; 81: 335-344.

38. Chang J, Da Silva JD, Sakai M, Kristiansen J, Ishikawa-Nagai S. The optical effect of composite luting cement on all ceramic crowns. J Dent 2009; 37: 937-943.

39. Chen XD, Hong G, Xing WZ, Wang YN. The influence of resin cements on the final color of ceramic veneers. J Prosthodont Res 2015; 59: 172-177.

40. Egilmez F, Ergun G, Cekic-Nagas I, Vallittu PK, Lassila LVJ. Comparative color and surface parameters of current esthetic restorative CAD/CAM materials. J Adv Prosthodont 2018; 10: 32-42.

41. Öztürk C, Çelik E, Özden AN. Influence of bleaching agents on the color change and translucency of resin matrix ceramics. J Esthet Restor Dent 2020; 32: 530-535. 